\title{
ARTICLE
}

\section{Association and linkage analysis of candidate chromosomal regions in multiple sclerosis: indication of disease genes in 12q23 and 7ptr-15}

\author{
Chun $\mathrm{Xu}, \mathrm{Y}$ amei Dai, Sten Fredrikson and Jan Hillert \\ D epartment of Neurology, K arolinska Institute, H uddinge University H ospital, Sweden
}

\begin{abstract}
Four recent genome-wide screen studies in multiple sclerosis (MS) identified a number of candidate regions for susceptibility genes in addition to the HLA complex in $6 \mathrm{p} 21$. H owever, none of these regions provided formally significant evidence for genome-wide linkage. We have investigated such regions in $\mathbf{4 6}$ Swedish multiplex MS families, 28 singleton families, 190 sporadic M S patients and 148 normal controls by parametric and nonparametric linkage and association analysis. 0 ne microsatellite marker, in 12q23, provided evidence for association in addition to suggestive transmission distortion and slightly positive linkage. In addition, a marker in 7ptr-15 showed a significant transmission distortion as well as a highly significant score in affected pedigree member analysis, but not quite significant deviations in association analysis. 0 ne of three markers in $5 p$, a region implicated in all four previous studies, showed a weakly positive lod score, but no other evidence of importance. M arkers in 2p23, 5q11-13, 6q25, 7q21-22, 11q21-23, 13q33-34, 16p13.2, 18p11.32-23, Xp21.3 provided little or no evidence of importance for MS. In summary, these data support the importance of genomewide screens in the identification of new candidate loci in polygenic disorders.
\end{abstract}

Keywords: multiple sclerosis; candidate regions; linkage analysis; genetic susceptibility

\section{Introduction}

Multiple sclerosis (MS), a chronic, inflammatory, autoimmune, demyelinating disorder of the central nervous system, is the most common cause of acquired neurological dysfunction arising in the second to fourth decades of life. ${ }^{1,2} \mathrm{~K}$ nowledge of the pathophysiological basis of MS is incomplete. H owever, genetic epidemiology clearly indicates that genetic factors are of impor-

Correspondence: $\mathrm{Dr}$ Chun $\mathrm{Xu}$, Department of Neurology $\mathrm{R} 54$, Karolinska Institute at $\mathrm{H}$ uddinge U niversity $\mathrm{H}$ ospital, S-14186 Huddinge, Sweden. Tel: +46858582299; Fax: 4687744822; E-mail: chun.xu@cnsf.ki.se

R eceived 18 March 1998; revised 15 June 1998; accepted 1 July 1998 tance for the risk of $\mathrm{MS}$, and a polygenic inheritance is most likely. ${ }^{3,4}$ A lthough the HLA gene complex has been clearly identified as important, many patients fail to carry the associated haplotype and estimations suggest that this locus only contributes a minor part of the overall genetic susceptibility. ${ }^{5}$ Recently, four groups $^{6-9}$ have completed full genomic screens using large numbers of microsatellite markers in high numbers of affected sibling pairs. Each screen used a different set of markers and identified mostly different chromosomal regions as being of possible importance. H owever, all studies confirmed the H L A gene complex in $6 \mathrm{p} 21$ and, in addition, suggested that a locus in 5p might be of importance. Thus, these data give some idea 
of where chromosomal regions suitable for hypothesis generation and further testing are located. ${ }^{10}$ The aim of this study was to investigate whether a number of these non-H LA loci play any role for the risk of MS in the Swedish ethnic group, by applying a combination of statistical analyses on familial and non-familial MS.

\section{Materials and Methods}

\section{Family Materials}

D NA samples were obtained from 286 individuals, including 207 individuals from 46 multiplex MS families and 79 individuals from 28 singleton MS families (Table 1). M S was diagnosed on the basis of clinical and paraclinical investigations. ${ }^{11}$ In cases where one or both parents were unavailable, D NA was obtained from unaffected siblings in order to allow derivation of parental haplotypes.

\section{Case-control Materials}

We investigated 190 unrelated Swedish patients with clinically define $M^{12}$ and 148 ethnically matched healthy controls in association analyses (Table 1 ). Most of patients with MS showed signs of intrathecal immunoglobulin production in cerebrospinal fluid analysis. Swedish ethnicity of M S patients determined the clinical setting. As healthy controls only individuals with Swedish names were accepted.

\section{Microsatellite Markers}

Sixteen microsatellite markers were selected (based on their location within or close to regions in $2 p 23,5 p 15,5 q 11,6 q 25$, $7 p t r, 7 q 21,11 q 21,12 q 23-24,13 q 33,16 p 13.2,18 p 11, x p 21$ ) that showed varying degrees of evidence for linkage in at least one of four previous genomic screen studies of MS affected sibling pairs. ${ }^{6-9}$ The markers chosen were either identical to ones used in the previous studies or mapped closely to the markers used (Table 2). Of the present markers, 11 contained dinucleotide repeats, four were tetranucleotide repeats and one was a trinucleotide repeat. The locations of markers were obtained from public domain databases (http:/ /www.hgmp.mrc.ac.uk, http://www.cephb.fr/ceph-généthonmap.html and http://cedar.genetics.soton.ac.uk/pub/).

\section{Genotyping}

A II 624 individuals were genotyped for the 16 selected markers. Genomic D NA was extracted from peripheral blood leukocytes using a modified salting-out protocol. ${ }^{13}$ Polymerase chain reaction (PCR) was employed in $7 \mu$ l reaction volumes. Primers were synthesised by Scandinavian $\mathrm{G}$ ene Synthesis A B and forward primers for each primer pair were labelled with 5'-FAM, HEX, or TET phosphoramidites (K öping, Sweden). O ptimal PCR condition were usually $95^{\circ} \mathrm{C}$ for $1 \mathrm{~min}, 55^{\circ} \mathrm{C}$ for $40 \mathrm{~s}$ and $72^{\circ} \mathrm{C}$ for $1 \mathrm{~min}$ with 30 cycles, by a PCR cycler G ene A mp 9600 (Perkin Elmer), but varied somewhat among the markers. $G$ enotyping was carried out in the semiautomatic GENESCA N/GENOTYPER system on A pplied Biosystems 377 DNA sequencing equipment. ${ }^{14} \mathrm{~A} \|$ samples of PCR product were diluted accordingly and $1.5 \mu \mathrm{l}$ was combined with $0.5 \mu \mathrm{l}$ internal size standard ( $G$ enescan - 350 or -500 TA M R A , A pplied Biosystems). The accuracy and reproducibility of automated sizing of fragments were further confirmed by randomly chosen repeated analyses of identical samples and two independent individuals reading data. Genotypes that were found to be inconsistent with inheritance or that were discordant between two analyses were either repeated or discarded.

\section{Statistical Analysis}

Two-point linkage analysis was performed with MLINK, version 5.10 of the LINKAGE package and FASTLINK, version $3.0 .{ }^{15,16}$ E qual recombination fractions were used for males and females. The age-dependent penetrance values were $0.7,0.35$ and 0.1 and the disease gene frequency was 0.001 .

Since the mode of inheritance for M S remains unclear and parametric linkage analysis can be highly sensitive to misspecification of the linkage model, several non-parametric analysis were performed:

1) A ffected pedigree member (APM) analysis was performed by the APM program, version $2.10 .{ }^{17} \mathrm{M}$ arker allele frequencies were estimated from 148 normal controls. H eterozygosity for each marker was estimated from these frequencies (see Table 2);

2) Non-parametric linkage (NPL) analysis of the GENE HUNTER package, version $1.1 ; i^{18}$ and

3) ETDT (extended transmission disequilibrium test) was carried out according to the method described by Sham and Curtis et al $^{19}$ using the software package ETDT version 1.4 .

\section{Association Analysis}

Comparisons of allele frequencies between cases and controls were calculated by the $\chi^{2}$ test for a $2 \times k$ contingency table and Fisher exact tests. For calculations of full allele distribution tables, rare alleles (expected numbers less than 5 ) were combined into a separate class. A s this was an exploratory

Table 1 Characteristics of the investigated M S families and sporadic patients

\begin{tabular}{|c|c|c|c|c|c|c|c|c|c|c|c|}
\hline & $\begin{array}{l}\text { No. of } \\
\text { families }\end{array}$ & $\begin{array}{l}\text { Total } \\
\text { ind. }\end{array}$ & $\begin{array}{l}\text { A ffected } \\
\text { ind. }\end{array}$ & aSP & aA N & $\mathrm{aPC}$ & $\mathrm{aCP}$ & $a G G$ & $\mathrm{aH}$ SP & & No. of ind. \\
\hline Families & & & & & & & & & & Population & \\
\hline multiplex & 46 & 207 & 104 & & & & & & & Sporadic M S patients & 190 \\
\hline singleton & 28 & 79 & 28 & & & & & & & Healthy controls & 148 \\
\hline Total & 74 & 286 & 132 & 26 & 19 & 12 & 5 & 4 & 2 & Total & 338 \\
\hline
\end{tabular}

ind: individuals; aSP: affected sibpairs; aA N : affected aunt (uncle)-nephew (niece) pairs; aPC: affected parent-child pairs; aCP: affected cousin pairs; aG G : affected grandparent-grandchild pairs; aH SP: affected half-sibpairs. 
study, no corrections of $P$ values due to multiple testing have been performed. Thus, the interpretation of $P$ values should be made with the large number of comparisons in mind.

\section{Results}

\section{Identification of Marker Allele Frequencies}

The allele frequencies for the 16 polymorphic markers were estimated and average observed heterozygosity rates were 0.795 from 148 Swedish controls (Table 2). In comparison with database information, a number of additional alleles were observed. H eterozygosity rates were generally higher than previously reported.

\section{Linkage and Association Analyses}

The results of A PM , ETDT, $\chi^{2}$, two-point lod score and NPL analyses for the 16 markers are shown in Tables 3 , 4, 5. A s shown, four candidate loci, $5 \mathrm{p} 15,7 \mathrm{ptr}-15$, and 12q23, each represented by a single marker, scored positively in various ways.

\section{$12 q 23$}

The marker D 12S1052, mapped to 12q23, a locus which scored slightly positive (lod score $=1.48$ ) for linkage in the report by $\mathrm{H}$ aines et $\mathrm{al}^{7}{ }^{7}$ scored slightly positive (NPL score $=0.95)$ in the non-parametric linkage analysis. In addition to a slight transmission distortion $(P<0.04)$, the strongest evidence for an importance in MS was obtained from the association study (Table 4). In addition to a significant deviation for the full contingency table, $\left(\chi^{2}=22.5, P<0.0004\right)$ the most common allele was significantly increased in frequency in M S patients $(41.2 \%$ vs $27.7 \%, \mathrm{P}<0.01)$.

\section{$7 p t r-15$}

Four published genomic screens in M S reported slightly positive lod scores, between 0.80 and 1.11, in the 7ptr15 chromosomal region. ${ }^{6-9}$ In our analysis, the D 7S513 marker showed a similarly weak NPL score of 0.73 . A more significant finding, however, may be the significant statistic of 6.92 ( $P<0.00001$, Table 3 ) provided by the APM analysis. On the other hand, the APM analysis is sensitive to incorrectly assigned allele frequencies. Thus, under or overestimated allele frequencies can lead to a bias in favour of sharing and produce false positive or false negative results. ${ }^{20}$ In addition, an increase in frequency of D 7S513-allele 2 in M S patients ( $13.8 \%)$ compared with controls $(5.32 \%)$ $\left(\chi^{2}=6.91, P<0.01\right.$, Table 4$)$.

\section{$5 p$}

The most consistent finding in the four previous genomic screens, apart from positive scores for the HLA complex in 6p21, was the observation of a putative susceptibility gene locus in $5 p .^{6-9} \mathrm{H}$ owever, this region was loosely defined, and the lod score peaks in four studies did not clearly overlap. In the present study, one of three selected markers showed a slightly positive NPL score $(0.95$, Table 3 ) of the GENEHUNTER package. Since this analysis is known to be

Table 2 Number of alleles, range of sizes and heterozygosity of markers used as observed in 148 Swedish healthy controls

\begin{tabular}{|c|c|c|c|c|c|}
\hline L ocus & $\begin{array}{l}\text { Chromosome } \\
\text { location }\end{array}$ & $\begin{array}{l}\text { No. of } \\
\text { alleles }\end{array}$ & $\begin{array}{l}\text { Repeat } \\
\text { type }\end{array}$ & $\begin{array}{l}\text { Size range } \\
\text { (bp) }\end{array}$ & $\begin{array}{l}\text { Hetero- } \\
\text { zyg. rate }\end{array}$ \\
\hline D 2S131 & $2 p 25-22$ & 14 & di & $227-257$ & 85 \\
\hline D 5S406* & $5 p 15.31$ & 14 & di & $157-185$ & 79 \\
\hline G ATA 84E $11^{*}$ & $5 p 15.31$ & 9 & tetra & $250-282$ & 80 \\
\hline D 5S407* & $5 p 15.1$ & 14 & $\mathrm{di}$ & $100-128$ & 75 \\
\hline D 5S427 & $5 q 11-13$ & 20 & di & $271-327$ & 81 \\
\hline D 6S305 & $6 q 25.2$ & 17 & di & $193-235$ & 84 \\
\hline D 7S513 & 7ptr-p15 & 17 & di & $175-211$ & 82 \\
\hline D 7S554 & $7 q 21-22$ & 11 & di & $216-238$ & 71 \\
\hline D 11S2000 & $11 q 21-23$ & 20 & tetra & $199-239$ & 87 \\
\hline D 12S1052 & $12 q 23$ & 7 & di & $142-174$ & 72 \\
\hline D 12S392 & 12q24-qter & 6 & tetra & $136-156$ & 79 \\
\hline D $13 S 285$ & $13 q 33-34$ & 9 & di & 90-112 & 81 \\
\hline D 16S748 & 16 p13.2 & 10 & tri & $182-214$ & 82 \\
\hline D 18S59 & $18 p 11.32-23$ & 10 & di & $147-169$ & 75 \\
\hline DXS1086* & X p21.3 & 11 & di & $245-273$ & 82 \\
\hline DXS1068* & X p21 & 7 & tetra & $243-265$ & 79 \\
\hline
\end{tabular}

The locations of markers were obtained from http://cedar.genetics.soton.ac.uk/pub/ *The distance between the markers D5S406 and GATA $84 E 11$ is 4.7cM; between G ATA $84 E 11$ and D 5 S407 37.5cM ; between D X S1086 and D X S1068 11.1cM . 
Table 3 Linkage analysis of putative candidate regions on chromosomes 2, 5, 6, 7, 11, 12, 13, 14, 16, 18, and X

\begin{tabular}{|c|c|c|c|c|c|c|c|c|c|c|c|}
\hline \multirow{3}{*}{$\begin{array}{l}\text { Candidate } \\
\text { regions }\end{array}$} & \multirow[b]{3}{*}{ locus } & \multicolumn{5}{|c|}{ Present study } & & & & & \\
\hline & & \multirow{2}{*}{$\frac{\text { APM }}{P \text { value }}$} & \multirow{2}{*}{$\begin{array}{l}\text { A-WTDT }{ }^{\mathrm{a}} \\
\text { P value }\end{array}$} & \multicolumn{2}{|c|}{ Case control } & NPL & \multicolumn{5}{|c|}{ Highest MLS value in the region } \\
\hline & & & & $\chi^{2}$ & Score & $P$ value & A merican & & British & Canadian & Finnish \\
\hline $2 \mathrm{p} 22-25$ & D2S131 & 0.18 & 0.2 & 0.88 & -0.48 & 0.73 & 1.71 & & - & (D2S119) 1.24 & - \\
\hline $5 p 15.3$ & D5S406 & 0.32 & 0.48 & 0.34 & 0.21 & 0.40 & - & & - & 4.24 & $\begin{array}{ll}(D 5 S 416) & 3.4\end{array}$ \\
\hline $5 p 15.3$ & GATA 84E 11 & 0.4 & 0.3 & 0.0009 & -0.03 & 0.51 & - & & - & - & (D5S1991) 2.5 \\
\hline 5p15.1 & D5S407 & 0.65 & $<0.02^{b}$ & 0.14 & 0.98 & 0.14 & - & & 1.9 & - & (D5S1992) 2.5 \\
\hline $5 q 11-13$ & D5S427 & 0.06 & 0.08 & 0.13 & 0.26 & 0.38 & (D5S815) & 1.14 & 2.7 & 0.2 & - \\
\hline $6 q 25.2$ & D6S305 & 0.03 & $<0.002^{b}$ & 0.43 & 0.09 & 0.45 & (D6S1693) & 0.64 & 2.4 & - & - \\
\hline $7 p t r-15$ & D7S513 & $<0.000001$ & 0.01 & 0.08 & 0.73 & 0.21 & (D 7S523) & 1.11 & 0.8 & 0.87 & - \\
\hline $7 q 21-22$ & D7S554 & 0.09 & 0.88 & 0.64 & 0.61 & 0.75 & 2.86 & & $\begin{array}{ll}(D 7 S 527) & 0.3\end{array}$ & - & - \\
\hline 11q21-23 & D11S2000 & 0.23 & 0.33 & 0.14 & 0.03 & 0.48 & (D 11S922) & 1.13 & (D 11S925) 0.2 & 1.38 & - \\
\hline 12q24-qter & D12S392 & 0.87 & 0.12 & n.d. & -0.61 & 0.75 & 1.71 & & - & - & - \\
\hline $12 q 23$ & D $12 S 1052$ & 0.29 & $<0.04^{b}$ & 0.0004 & 0.95 & 0.13 & 1.48 & & - & - & - \\
\hline $13 q 33-34$ & D13S285 & 0.79 & 0.18 & 0.09 & 0.00 & 0.50 & 0.87 & & - & - & - \\
\hline 16p13.2 & D 16S748 & 0.23 & 0.24 & 0.29 & 0.00 & 0.5 & 1.75 & & (D 16S287) 0.6 & - & - \\
\hline 18p11.32-23 & D18S59 & 0.99 & 0.5 & 0.93 & -1.25 & 0.92 & (D 18S66) & 0.93 & - & 0.56 & - \\
\hline Xp21.3 & DXS1086 & 0.81 & 0.41 & 0.97 & -0.75 & 0.81 & - & & - & - & - \\
\hline Xp21 & DXS1068 & 0.13 & 0.48 & 0.68 & 0.57 & 0.21 & - & & (DXS991) 1.8 & 1.85 & - \\
\hline
\end{tabular}

${ }^{2} \chi^{2}$ for allele-wise TDT; ${ }^{b}$ see Table 5 for details; ' -' indicates no evidence for linkage 
Table 4 D istribution of allele frequencies (\%) of markers of four potential important regions in M S patients and healthy controls

\begin{tabular}{|c|c|c|c|c|c|c|c|c|c|c|c|c|c|c|c|c|}
\hline \multirow[b]{2}{*}{ L oci } & \multicolumn{16}{|c|}{ D ifferent alleles in each locus } \\
\hline & 1 & 2 & 3 & 4 & 5 & 6 & 7 & 8 & 9 & 10 & 11 & 12 & 13 & 14 & 15 & 16 \\
\hline \multicolumn{17}{|l|}{ D 5S406 } \\
\hline MS (\%) & 1.6 & 1.2 & 27.4 & 12.9 & 9.1 & 42.5 & 0.5 & 1.1 & 1.1 & 1.6 & 1.1 & & & & & \\
\hline Control (\%) & 1.6 & 1.6 & 31.1 & 16.3 & 11.1 & 31.6 & 0 & 2.1 & 2.6 & 1.6 & 0.5 & & & & & \\
\hline \multicolumn{17}{|l|}{ G A TA $84 \mathrm{E} 11^{\circ}$} \\
\hline M S (\%) & 2.7 & 11.8 & 9.6 & 12.3 & 8.6 & 2.3 & 4.1 & $25^{b}$ & 18.2 & 5.5 & & & & & & \\
\hline Control (\%) & 4.3 & 7.7 & 7.1 & 7.4 & 4.9 & 2.9 & 1.4 & 40.6 & 18.6 & 5.1 & & & & & & \\
\hline \multicolumn{17}{|l|}{ D 5S407 } \\
\hline M S (\%) & 1.5 & 14.7 & 1.5 & 9.6 & 8.8 & 7 & 4.4 & 15.8 & 23.5 & 9.6 & 1.1 & 0.7 & 1.5 & 0.4 & & \\
\hline $\begin{array}{l}\text { Control (\%) } \\
\text { D 6S305 }\end{array}$ & 0.6 & \multicolumn{4}{|c|}{ D 6S305 } & 4.5 & 4.5 & 15 & 18.5 & 12.1 & 0.6 & 1.3 & 0.3 & 1.3 & & \\
\hline MS (\%) & 1.1 & 22.3 & 1.7 & 1.1 & 2.3 & 1.7 & 15.4 & 7.4 & 4.6 & $6.9^{\mathrm{a}}$ & 5.1 & 16 & 5.7 & 3.4 & 0.6 & 4.6 \\
\hline Control (\%) & 1.1 & 21 & 1.1 & 1.1 & 2.2 & 1.7 & 10.2 & 5.1 & 6.8 & 15.3 & 8 & 15.9 & 2.8 & 2.3 & 2.3 & 2.8 \\
\hline \multicolumn{17}{|l|}{ D 7S513 } \\
\hline M S (\%) & 5.8 & 21.3 & $13.8^{b}$ & 2.9 & 4 & 9.2 & 5.2 & 21.3 & 3.5 & 9.8 & 3.5 & & & & & \\
\hline $\begin{array}{l}\text { Control (\%) } \\
\text { D 12S1052 }\end{array}$ & 12.2 & 20.2 & 5.3 & 6.4 & 3.2 & 8 & 9 & 21.3 & 3.2 & 7.5 & 3.7 & & & & & \\
\hline M S (\%) & 15.7 & $41.2^{\mathrm{a}}$ & 27.2 & 10.1 & 3.7 & $1.4^{b}$ & & & & & & & & & & \\
\hline Control (\%) & 12.3 & 27.7 & 34.6 & 9.6 & 8.2 & 7.7 & & & & & & & & & & \\
\hline
\end{tabular}

${ }^{\mathrm{a}} \mathrm{P}<0.02 ;{ }^{b} \mathrm{P}<0.01 ;{ }^{c}$ overall distribution of alleles in M S vs controls differ $(\mathrm{P}<0.001)$; ${ }^{\text {o }}$ overall distribution of alleles in M S vs controls differ ( $P<0.0005$ ); D 12S1052 is located on 12q23; D 5S406, G A TA 84E 1 and D 5S407 are located in 5p15; D 6S305 is located in 6q25.2; D 7 S513 is located on 7ptr-15.

conservative as a single point test, ${ }^{21}$ we have in addition applied multipoint analysis to these three markers. However, since the middle marker scored less positively, this procedure did not improve the evidence for linkage. On the other hand, this marker showed promising signs of allelic association as given in Table 4 . In addition, D5S407-allele 1 showed transmission to affected offspring more often than expected $(P<0.02$, Table 5).

\section{Other markers}

No evidence of linkage or association were found for the markers D2S131 (2p23), D5S427 (5q), D6S305 (6q25), D 7S554 (7q), D 11S2000 (11q21-23), D 12S392 (12q24-qtr), D 13S285 (13q33-34), D 16S748 (16p12), D 18S59 (18p11) and DX S1086/DX S1068 (X p21) in the 74 Swedish MS families with parametric, non-parametric linkage analyses, transmission disequilibrium and case-control association analyses. In fact, when we evaluated these 12 markers under different inheritance models by classic two-point linkage analyses, all observed lod scores were negative. We conclude that there is no evidence of significant MS in these regions in the Swedish population.

\section{Discussion}

The role of genetic factors in the aetiology of MS has been clearly demonstrated, but the loci determining susceptibility to this disease remain largely unidentified. R ecently, genome-wide scans of large numbers of M S-affected sibling pairs ${ }^{6-9}$ have greatly accelerated the search for additional susceptibility loci in MS. A Ithough these studies failed to identify any locus of significant importance, in addition to the $H L A$ gene

Table 5 Transmission disequilibrium test of markers in three candidate loci in multiplex M S families

\begin{tabular}{lccccccccccccc}
\hline A llele & 1 & 2 & 3 & 4 & 5 & 6 & 7 & 8 & 9 & 10 & 11 & 12 & 13 \\
\hline D 5S407 (5p15) & & & & & & & & & & & & & \\
$\quad$ Transitted & $17^{\mathrm{a}}$ & 0 & 11 & 4 & 2 & 5 & $5^{\mathrm{a}}$ & 15 & 10 & 0 & 1 & \\
$\quad$ N ot transitted & 6 & 1 & 7 & 5 & 2 & 3 & 14 & 17 & 12 & 1 & 2 & \\
D 6S305 (6q25.2) & & & & & & & & & \\
$\quad$ Transitted & 16 & 1 & 1 & 0 & $23^{\mathrm{c}}$ & 3 & 5 & 10 & 7 & $6^{\mathrm{b}}$ & 6 & 4 & 0 \\
$\quad$ Not transitted & 14 & 0 & 0 & 2 & 12 & 5 & 4 & 9 & 6 & 22 & 6 & 1 & 1 \\
D 12S1052 (12q23) & & & & & & & & & & \\
$\quad$ Transitted & 14 & 24 & 24 & $6^{\mathrm{d}}$ & 5 & 1 & 1 & & & & & \\
$\quad$ N ot transitted & 16 & 21 & 16 & 15 & 7 & 0 & 0 & & & & & \\
\hline
\end{tabular}

${ }^{\mathrm{a} P}<0.02 ;{ }^{b} \mathrm{P}<0.002 ;{ }^{\mathrm{C}} \mathrm{P}$ value is on the borderline of significant; ${ }^{\mathrm{d}} \mathrm{P}=0.039$. 
complex, they did reveal multiple loci $(2 p 23,5 p, 5 q, 6 q$, $7 p, 7 q, 11 q, 12 q, 13 q, 16 p, 18 p, \times p 21$ ) worthy of further study. In this study, we have investigated some of these putative candidate regions in 74 Swedish MS families and unrelated MS patients and controls using 16 microsatellite markers within or close to previously identified regions of possible importance. We observed suggestive evidence for importance of the candidate regions in 5p15, 6q25, 7ptr-15 (Table 3), and 12q23 (Tables 3, 4, 5). E specially, alleles of markers D 12S1052 (12q23) showed significant association with MS ( $P=0.0004)$. H owever, there were only weak, usually non-significant, findings by classic linkage analysis, N PL and extended transmission analysis (ETDT). Nevertheless, our findings indicate that it may be possible to find association in only weakly linked loci. The GE NE HUNTER is known to be very conservative as a single point test. ${ }^{23}$ We had applied multipoint analysis to three markers in $5 p$.

The application of linkage analysis in polygenic diseases like MS and diabetes mellitus is problematic for several reasons. For instance, ordinary two-point linkage analysis is hampered by the difficulty in defining a genetic model that adequately explains the observed inheritance pattern. In order to limit this problem, we additionally applied the model-free A PM method, ${ }^{17}$ the non-parametric linkage (NPL) analysis of the GENEHUNTER package, ${ }^{18}$ and the extended TDT analysis. ${ }^{19}$

Linkage analysis has been a successful tool in the identification of major genes in mono- or oligogenic disorders. H owever, for complex diseases, the power of linkage analysis may be too limited to detect genes of modest effect. Thus, large genomic scans in diseases such as insulin-dependent diabetes mellitus (IDDM) and M S have usually only provided slight evidence for an importance of the different loci, only occasionally fulfilling stringent criteria for genome-wide significance. ${ }^{22}$ In fact, association analysis, as in transmission disequilibrium text or case-control analysis, is likely to be more powerful and may identify more circumscribed chromosomal regions than linkage. Thus, it has been suggested that the successful genetic analysis of complex diseases will be performed as large-scale testing by association analysis. ${ }^{9}$ For the same reasons, it is also relevant to study weakly defined loci originating from genome-wide linkage analysis in independent data sets. In this study, we find that a few previously identified loci may indeed be of importance also in the present population, corroborating their possible importance.
For a marker in 12q23, we report the presence of association, mainly in the case-control analysis $(P<0.0004)$, but also slightly in the transmission analysis $(P<0.04)$, in spite of weak evidence for linkage (an NPL score of 0.95 ) by NPL and ETDT (Tables 3, 4 and 5). For the marker in 7ptr-15, the evidence for linkage was similarly weak and somewhat variable. On the other hand, as for $12 \mathrm{q} 23$, there were also indications of association, although somewhat less clear-cut. The presence of association without significant linkage might signify that the studied alleles explain only a minor proportion of the variance of a trait. Thus, certain alleles may occur more often in affected individuals but are less useful in predicting disease status within pedigrees. ${ }^{23} \mathrm{O}$ the other hand, a modest association with a common allele may in fact contribute significantly to the prevalence of disease in the population. In addition, an important benefit of an observed association is that it provides a tool to further delineate the relevant chromosomal region, which greatly facilitates the eventual identification of the responsible genetic factor.

In addition, we observe both indicative linkage and possible association with markers in $5 p$ (Tables 3,4$)$. Thus, our findings add to the general impression that this locus may indeed be of importance in MS.

The data from our study provide no significant evidence in favour of linkage or association with M S for the putative candidate regions on chromosomes $2 \mathrm{p} 23$, 5q11-13, 6q25, 7q21-22, 11q21-23, 13q33-34, 16p13.2, $18 p 11$ and $X$ p21.3. This may be explained in a number of different ways:

1) There is a heterogeneity in the genetically determined susceptibility to MS between the Swedish population and the populations studied in the previous scans; ${ }^{6-9}$ or

2) the present material is too small to give the analysis adequate statistical power; or

3) these loci were 'false positives', and lack importance in all populations.

Only further analysis in different populations will eventually give the answer to this question.

\section{Acknowledgements}

This study was supported by the Swedish Medical R esearch Council (project numbers: 11023 and 11220), the Society for the Neurologically Disabled, the Sigurd and Elsa Goljes Minne Foundation, the Karolinska Institute, the $M$ agn B ergvalls Foundation, the $A$ ke W iberg Foundation, the B ibbi 
and Nils Jensens Foundation and the $M$ arcus Borgströms Foundation.

\section{References}

$1 \mathrm{H}$ auser SL, A ubert C, B urks I S et al: A nalysis of human T lymphotropic virus sequences in multiple sclerosis. $\mathrm{N}$ ature 1986; 322: 176-177.

$2 \mathrm{H}$ auser SL: Multiple sclerosis and other demyelinating diseases. In: I sselbacher $\mathrm{K}$ et al (eds). H arrison's P rinciples of Internal M edicine, 13th edn. M cG raw-H ill; N ew Y ork, 1994, 2287-2295.

3 Sadovnick A D , A rmstrong H, R ice G $P$ et al: A population based on twin study of multiple sclerosis in twins: update. A nn Neurol 1993; 33: 281-285.

4 Ebers GC, Sadovnick AD, Risch NJ and the Canadian Collaborative Study Group: A genetic basis for familial aggregation in multiple sclerosis. Nature 1995; 377: 150-151.

$5 \mathrm{R}$ isch $\mathrm{N}$ : A ssessing the role of H LA -linked and unlinked determinants of disease. Am J Hum Genet 1987; 40: 1-14.

6 Sawcer S, Jones H B, Feakes R et al: A genome screen in multiple sclerosis reveals susceptibility loci on chromosome 6p21 and 17q22. N at G enet 1996; 13: 464-468.

7 Haines J L, Ter-M inassian M, B azyk A et al: A complete geneomic screen for multiple sclerosis underscores a role for the major histocompatibility complex. N at G enet 1996; 13: 469-471.

8 Ebers GC, Kukay K, Bulman DE et al: A full genome search in multiple sclerosis. Nat G enet 1996; 13: 472-476.

9 Kuokkanen S, G schwend M, R ioux JD et al: G enomewide scan of multiple sclerosis in Finnish multiplex families. A m J H um G enet 1997; 61: 1379-1387.

10 Dyment DA, Sadnovich AD, E bers GC: Genetics of multiple sclerosis. $\mathrm{H}$ um M ol G enet 1997; 6: 1693-1698.

11 Poser CM, Paty DW, Scheinberg L, M CD onald WI et al: New diagnostic criteria for multiple sclerosis: guidelines for research protocols. A nn Neurol 1983; 13: 227-231.
12 Schumacher GA, Beebe B, Kibler RF: Problems of experimental trials of therapy in multiple sclerosis: report by the panel on the evaluation of experimental trials of therapy in multiple sclerosis. A nn N Y A cad Sci 1965; 122: 552-568.

13 Olerup 0, A Idener A, Fogdell A: HLA-DOB 1 and -DQA 1 typing by PCR amplification with sequencespecific primers (PCR -SSP) in 2 hours. Tissue Antigens 1993; 41: 119-134.

14 Reed PW, D avies J L, Copeman JB et al: Chromosomespecific microsatellite sets for fluorescence-based, semiautomatic genome mapping. N at G enet 1994; 7: 390-395.

15 G upta SK, Schäffer A A, C ox A L, D warkadas S, Z waenepoel W: Integrating parallelization strategies for linkage analysis. Comput Biomed Res 1995; 28: 116-139.

16 Terwilliger JD, $\mathrm{Ott} \mathrm{J:} \mathrm{H}$ andbook of $\mathrm{H}$ uman Genetic L inkage. Johns $\mathrm{H}$ opkins U niversity Press: $\mathrm{B}$ altimore and L ondon, 1994.

17 Weeks DE, Schmidtke J: The affected-pedigree-member method of analysis. A m J H um G enet 1988; 42: 315-326.

18 K ruglyak L, Daly MJ, R eeve-Daly M P, L ander E S Parametric and nonparametric linkage analysis: a unified multipoint approach. Am J Hum Genet 1996; 58: 1347-1363.

19 Sham PC, Curtis D: An extended transmission disequilibrium test (TDT) for multi-allele marker loci. A nn H um G enet 1995; 59: 323-326.

20 Holmans $\mathrm{P}$, Clayton D: Efficiency of typing unaffected relatives in an affected-sib-pair linkage study with singlelocus of and multiple tightly linked markers. A m J H um G enet 1995; 57: 1221-1232.

21 Terwilliger JD, Shannon WD, L athrop G M et al: True and false positive peaks in genomewide scans: applications of length-biased sampling to linkage mapping. A m J H um G enet 1997; 61: 430-438.

22 Bennett ST, Wilson AJ, Esposito L et al: Insulin VNTR allele-specific effect in type 1 diabetes depends on identity of untransmitted paternal allele. The IM D IA B G roup. N at G enet 1997; 17: 350-352.

23 Lander ES, Schork NJ: Genetic dissection of complex traits. Science 1994; 265: 2037-2048. 